\title{
Mechanical, Durability and Microstructure Properties of Cold Asphalt Emulsion Mixtures with Different Types of Filler
}

Ahmed I. Nassar ${ }^{1 *}$, Mahmoud Khashaa Mohammed ${ }^{2}$, Nicholas Thom ${ }^{1}$ and Tony Parry ${ }^{1}$

${ }^{1}$ Nottingham Transportation Engineering Centre, Department of Civil Engineering, Faculty of Engineering, University of Nottingham, University Park, Nottingham NG7 2RD, UK.

${ }^{2}$ Civil Engineering Department, Faculty of Engineering, University of Anbar, Anbar Governorate, Iraq.

*Corresponding author: E-mail: evxan1@ nottingham.ac.uk, ah.nassar@yahoo.com. 


\begin{abstract}
The primary aim of this study is to investigate the enhancement of Cold Asphalt Emulsion Mixtures (CAEMs) using binary and ternary blended fillers (BBF and TBF), including an indepth assessment of the microstructure. Ordinary Portland cement (OPC), fly ash (FA) and ground granulated blast furnace slag (GGBS) were used for the BBF while silica fume (SF) was added to the BBF to obtain TBF. The mechanical and durability results indicated that the TBF was more suitable than the BBF for the production of CAEMs. The microstructural assessment indicated that the effect of BBF on the internal microstructure of CAEMs was slightly negative and more noticeable in CAEMs containing FA. It is proposed that the addition of SF to BBF mixtures can eliminate the delay in formation of hydration products caused by the bitumen emulsion. Overall, the research suggests that the use of BBF-CAEMs might be appropriate for pavements in cold climate whereas TBF-CAEMs would be effective in road pavements exposed to severe conditions both in hot and cold climates.
\end{abstract}

Keywords: Cold Asphalt Emulsion Mixtures; Blended fillers; Stiffness modulus; Repeated load axial test; Durability; Microstructure; Delay hydration process 


\section{Introduction}

Nowadays, environmental issues about reducing energy consumption, reducing $\mathrm{CO}_{2}$ emissions and managing wastes are being increasingly articulated and have been gaining attention worldwide. One of the most significant trends towards more eco-friendly asphalt mixes is the use of material such as recycled asphalt pavement, municipal solid waste incineration ash, construction and demolition waste material, cement kiln dust and coal ash [1-8].

Due to the many significant environmental and economic benefits that can be derived from using cold asphalt mixtures (CAMs), several research projects have been performed to study and develop the properties of these mixtures. The development of CAMs has commonly been by utilizing waste material/ by-products while achieving satisfactory hot mix asphalt (HMA) properties $[6,7,9,10]$. However, CAMs for sustainable and resilient pavements still has to meet the requirements of carrying heavy traffic loads from a mechanical perspective. Additionally, the properties of CAMs need to resist the impact of the environment from a durability perspective. In the current research, these two features will be termed as engineering properties. The enhancement of the engineering properties of CAMs mainly depends on the type, quantity and quality of the raw materials used. This might be considered as one of the most important factors to extend the use of CAMs for the use as a surface course.

Fillers can play a major role controlling the engineering properties of asphalt mixtures. It has been demonstrated that filler can significantly influence permanent deformation resistance, stiffness, fracture resistance, and moisture susceptibility of asphalt concrete $[11,12]$. A recent development aimed at achieving excellent engineering properties of CAMs is the use of manufactured fillers. This kind of filler is produced as a blend of reactive, semi-reactive and non-reactive natural fillers $[6,7,13,14]$. In this study, binary blended fillers (BBFs) contain a combination of fly ash (FA) or granulated blast furnace slag (GGBS) with ordinary Portland cement (OPC), while the ternary blended fillers (TBFs) are a combination of BBFs with silica fume (SF). These fillers are used for many reasons. FA, GGBS, SF are considered to be some of the most used supplementary cementitious material alternatives. Furthermore, their availability worldwide in substantial quantities can provide social, economic, and environment benefits.

An experimental study by Oruc, Celik and Akpinar [13] assessed the mechanical properties of emulsified asphalt mixtures including 0-6\% OPC, which was substituted for mineral filler. Their findings showed a remarkable improvement with a high percentage of OPC treatment, 
recommending these mixtures to be used as a structural layer. Al-Busaltan, Al Nageim, Atherton and Sharples [6] confirmed the enhancement of close graded CAEM to a stage where its mechanical properties were comparable to those of traditional asphalt concrete mixtures. The improvement was due to the replacement of the conventional mineral filler with a domestic fly ash. Al-Hdabi, Al Nageim, Ruddock and Seton [15] showed a significant improvement in mechanical properties and water damage resistance of cold rolled asphalt by incorporating a biomass fly ash with cement. Recently, the influence of chemical additives including OPC, hydrated lime (HL), and a combination of HL and GGBS on recycled mixture performance was investigated by $\mathrm{Du}[16]$. The results showed that hydration products can increase the stiffness and cohesion of the asphalt mastic of the recycled mixture [16].

A comparison study between using coal ash and OPC in cold recycled asphalt mixtures was carried out by Modarres and Ayar [1]. The results revealed that the application of coal waste powder improved the mechanical properties of cold recycled asphalt material, but it could not achieve a positive impact on moisture damage resistance. Based on these comparisons, coal ash was found to have comparable effects to OPC. While previous studies have highlighted the importance of using OPC, HL and some specific kinds of fly ash in developing CAMs, there is a need to develop more sustainable CAMs using artificial by-products such as FA, GGBS and SF in combination with OPC. The purpose is to reduce the potential increase in production costs and environmental issues particularly in the manufacturing process of both cement and lime. However, the availability of alternative cement materials should be considered when choosing the type of fillers in CAMs.

Pouliot, Marchand and Pigeon [17] showed that the presence of a small quantity of bitumen emulsion in cement mortar had a delaying effect on the cement hydration. Furthermore, Du [18] agreed with this study and proposed a mechanism for the hydration process delay. He suggested that some of the bitumen droplets and cement particles come into contact due to intensive chemical adsorption, and as a result, some of the cement particles are encapsulated by an asphalt film, causing a delay or interruption in the hydration reaction. A study carried out by Wang, Shu, Rutherford, Huang and Clarke [19] showed that the total hydration heat decreased with an increase in bitumen to cement ratio in CAEM. Also, the study revealed that the addition of bitumen emulsion significantly influenced cement hydration behaviour in CEAM. In contrast, a recent experimental study carried out by Fang, Garcia, Winnefeld, Partl and Lura [20] revealed that the behaviour of bitumen emulsion in the presence of cement and filler is still unclear and may slightly retard or accelerate cement hydration, but has no significant effect on the degree of 
cement hydration. These research studies have demonstrated developments in the properties of CAEMs by using different types of filler. However, this raises an important question as to how these fillers (cement/artificial by-products) interact with bitumen emulsion and affect the hydration and microstructural characteristics of CAEMs.

\section{Research significance}

This study aims to develop special types of CAEM by using artificial by-products such as FA, GGBS and SF in combination with OPC. Accordingly, it is hoped that wider utilization of CAEMs in the construction of highway and pavement materials (with both environmental and economic impacts) can be derived from the current research. Meanwhile, this work is designed to contribute to a deeper understanding of the microstructure and internal composition of the mixes concerned.

\section{Material and testing program}

\subsection{Material characteristics}

The aggregate used in this study was crushed limestone. The physical properties of the aggregate were: apparent density $2.70 \mathrm{Mg} / \mathrm{m}^{3}$; absorption $0.4 \%$; Los Angeles Coefficient 28 . The gradation of the aggregate was within the limits of $0 / 14 \mathrm{~mm}$ size close graded surface course, according to BS EN 13108-1. This selection was made in order to ensure an appropriate interlock between the aggregate particles in the mixtures as recommended by the European Standard [21]. The gradation of the aggregate is shown in Fig. 1. The amount of mineral filler (limestone-passing sieve $0.063 \mathrm{~mm}$ ) was selected to be $5 \%$ of the total weight of the aggregate.

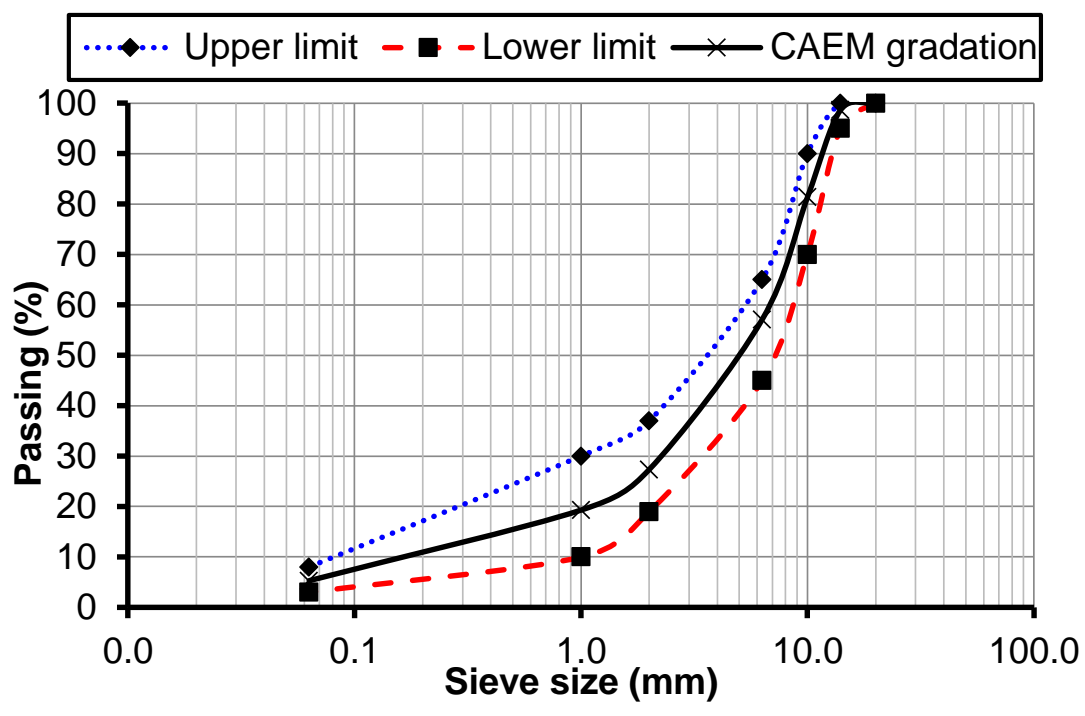


Fig. 1. Limestone aggregate gradation of $0 / 14 \mathrm{~mm}$ size close graded surface course according to BS EN 13108-1.

A commercial cationic slow setting bituminous emulsion, C60B5, was used to manufacture the CAEMs. This type of emulsion contains $60 \%$ residual bitumen content of $40 / 60$ pen base binder with a softening point of $52{ }^{\circ} \mathrm{C}$. The high stability and high adhesion of such cationic emulsion were the reason for selection as recommended by Nikolaides [22] and Thanaya [23].

Ordinary Portland cement (OPC) CEM I, 42.5 N, obtained from Cemex, was used in this study. A combination of OPC, fly ash, (class F) according to ASTM C-618, and GGBS obtained from Cemex and Hanson respectively, were used for the BBF mixtures. Densified silica fume (SF) produced by Elkem Microsilica was used as an additional mineral filler for the TBF mixtures.

A detailed characterization was carried out to investigate the chemical and physical properties of the selected fillers. The chemical composition of fillers (major oxidises) was analysed by EDX, energy dispersive X-ray fluorescence spectrometer. The results are presented in Table 1. Scanning electron microscopy (SEM) was used for determining the morphology of fillers, as shown in Fig. 2. SEM analysis was implemented under a resolution of 3-4 $\mathrm{nm}$ and an accelerated voltage of $15 \mathrm{kV}$.

Table 1. Chemical composition of fillers and cement

\begin{tabular}{lccccc}
\hline & OPC & FA & GGBS & SF & LF \\
\hline $\mathrm{Na}_{2} \mathbf{O}$ & 0.56 & 1.27 & 0.28 & 0.17 & -- \\
$\mathbf{M g O}$ & 2.04 & 1.76 & 6.89 & 0.36 & -- \\
$\mathbf{A l}_{2} \mathbf{O}_{3}$ & 4.11 & 25.14 & 11.21 & 0.39 & -- \\
$\mathrm{SiO}_{2}$ & 19.84 & 51.32 & 35.65 & 97.95 & 1.97 \\
$\mathrm{SO}_{3}$ & 5.41 & 1.90 & 2.43 & -- & -- \\
$\mathrm{K}_{2} \mathrm{O}$ & 1.06 & 4.24 & 0.64 & 0.89 & -- \\
$\mathrm{CaO}$ & 64.35 & 2.57 & 41.42 & 0.24 & 98.03 \\
$\mathrm{TiO}_{2}$ & 0.25 & 1.29 & 0.63 & -- & -- \\
$\mathbf{F e}_{2} \mathbf{O}_{3}$ & 2.39 & 9.77 & 0.26 & -- & -- \\
$\mathbf{P}_{2} \mathbf{O}_{5}$ & -- & 0.74 & -- & -- & -- \\
$\mathbf{M n O}$ & -- & -- & 0.60 & -- & -- \\
\hline
\end{tabular}



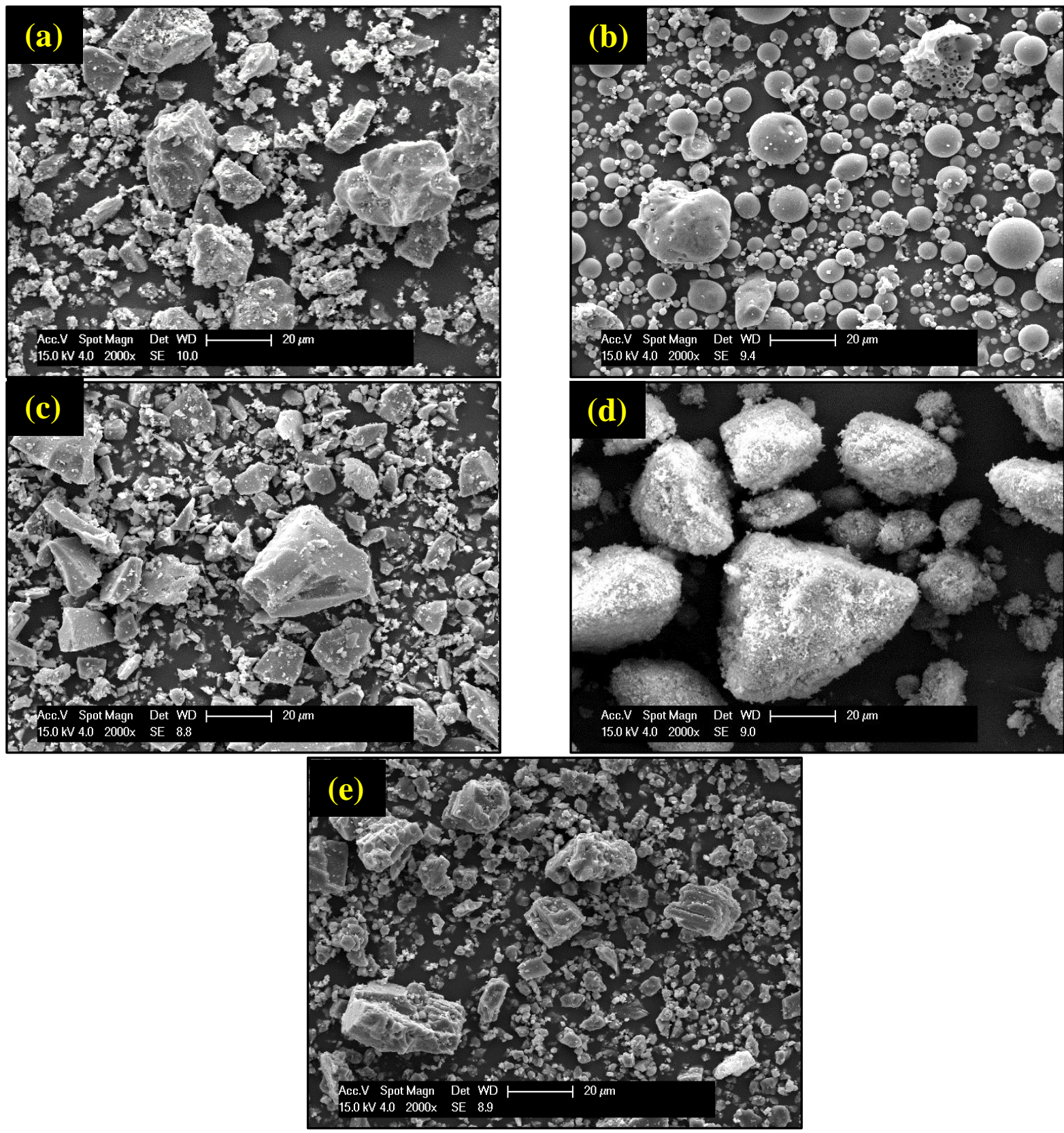

Fig. 2. Morphology of fillers and cement: (a) OPC; (b) FA; (c) GGBS; (d) SF; (e) LF

\subsection{Mix proportions and sample preparation}

In this study, OPC, FA, and GGBS were used to fully replace the conventional limestone filler in CAEMs, while SF was used as an additive as recommended in the literature $[6,7]$. BBFs containing $80 \%$ FA/GGBS and 20\% OPC (C-FA and C-GGBS) were used for BBF-mixtures. Meanwhile, TBFs consisted of $80 \%$ FA/GGBS and 20\% OPC with additional SF of $20 \%$ and $40 \%$ of combined (FA/GGBS+OPC) weight were used for TBF-mixtures (C-FA-20SF, C-FA40SF, C-GGBS-20SF and C-GGBS-40SF). 
A performance-based mix design approach was adopted to optimize the mix proportions for CAEM using a statistical technique described in a previous research work [24]. According to this procedure, pre-wetting water and optimum bitumen emulsion contents were $2.12 \%$ and $6.75 \%$ of total weight of aggregate, respectively.

The mixture proportions by mass of Marshall specimens are summarised in Table 2. The mixing process was carried out using a Sun and Planet mixer. After that, impact compaction (Marshall Hammer) was utilized to compact the specimens; 75 blows were applied to each face. The Marshall compaction was selected due to it is convince to produce a suitably dense mixture After compaction, the specimens were cured in their moulds (in a sealed condition) for $24 \mathrm{hrs}$ and then they were extruded. All the specimens were then conditioned in a thermostatically controlled air chamber at $20^{\circ} \mathrm{C}$. This curing temperature was selected as an approximation of the actual condition of CAEMs on site as well as to avoid any early ageing of the binder [25-27].

Table 2. Details of the mix proportions of CAEMs

\begin{tabular}{|c|c|c|c|c|c|c|c|c|c|c|}
\hline \multirow{2}{*}{\multicolumn{2}{|c|}{$\begin{array}{c}\text { Mixture } \\
\text { Types }\end{array}$}} & \multirow{2}{*}{$\begin{array}{c}\text { Mixtures } \\
\text { (g) }\end{array}$} & \multirow{2}{*}{$\begin{array}{c}\text { Aggregate } \\
\text { (g) }\end{array}$} & \multicolumn{5}{|c|}{ Filler combinations (g) } & \multirow{2}{*}{$\begin{array}{c}\text { Bitumen } \\
\text { Emulsion }(\mathrm{g})\end{array}$} & \multirow{2}{*}{$\begin{array}{c}\text { Pre-wetting } \\
\text { Water }(\mathrm{g})\end{array}$} \\
\hline & & & & OPC & FA & GGBS & SF & $\mathrm{LF}$ & & \\
\hline \multirow{2}{*}{$\frac{\omega}{n}$} & \multirow{2}{*}{$\stackrel{\mathscr{e}}{. 凶}$} & C-FA & 878.2 & 8.8 & 35.1 & - & - & - & 59.3 & 18.6 \\
\hline & & C-GGBS & 878.2 & 8.8 & - & 35.1 & - & - & 59.3 & 18.6 \\
\hline \multirow{4}{*}{$\stackrel{T}{e}$} & \multirow{4}{*}{$\stackrel{\mathscr{\Xi}}{a}$} & C-FA-20SF & 878.2 & 8.8 & 35.1 & - & 8.8 & - & 59.3 & 18.6 \\
\hline & & C-GGBS-20SF & 878.2 & 8.8 & - & 35.1 & 8.8 & - & 59.3 & 18.6 \\
\hline & & C-FA-40F & 878.2 & 8.8 & 35.1 & - & 17.6 & - & 59.3 & 18.6 \\
\hline & & C-GGBS-40SF & 878.2 & 8.8 & - & 35.1 & 17.6 & - & 59.3 & 18.6 \\
\hline \multirow{3}{*}{ 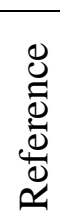 } & \multirow{3}{*}{$\cdot \stackrel{\mathscr{D}}{\Xi}$} & LF-mix & 878.2 & - & - & - & - & 43.9 & 59.3 & 18.6 \\
\hline & & OPC-mix & 878.2 & 43.9 & - & - & - & - & 59.3 & 18.6 \\
\hline & & HMA & 878.2 & - & - & - & - & 43.9 & \multicolumn{2}{|c|}{$45.18 \mathrm{~g}$ base binder $(40 / 60)$} \\
\hline
\end{tabular}

Three additional reference mixes were tested for comparison purposes. The first was untreated CAEM with conventional LF (LF-mix) having a similar design to other CAEMs. The second was CAEM fully treated with 5\% OPC only (OPC-mix). The third was standard hot mix asphalt (HMA). This mix contained the same aggregate type, gradation and base binder (40/60) as used in the other CAEMs; the bitumen content in the HMA was $4.9 \%$ as recommended by the British 
Standard [21]. All CAEMs were mixed and compacted at ambient temperature $\left(20^{\circ} \mathrm{C}\right)$ while the HMA was mixed and compacted at $165^{\circ} \mathrm{C}$ using 75 blows applied to each face.

\section{Experimental program and tests performed}

\subsection{Indirect tensile stiffness modulus (ITSM)}

The stiffness gain (curing trend) of reference CAEMs (LF-mix and OPC-mix) and treated CAEMs (BBF and TBF) were monitored over a period. The non-destructive stiffness test, ITSM, was selected for assessing the stiffness modulus over a period of approximately three months. It was performed at different ages, i.e. 3, 5, 7, 14, 28, 45 and 84 days. Three specimens per mix were tested under the same conditions. The ITSM was chosen in order to carry out the test on the same set of specimens to nullify variability in the mixtures and to derive reliable trends for stiffness evolution. Stiffness modulus is considered as an indicator of the structural condition of a mixture because it is directly related to the capacity of the asphalt material to distribute traffic loads. The test was carried out according to BS EN 12697-26 [28], as shown in Table 3.

Table 3. ITSM test configuration based on BS EN 12697-26

\begin{tabular}{ll}
\hline Item & Range \\
\hline Specimen diameter & $100 \pm 2 \mathrm{~mm}$ \\
Transient peak horizontal deformation & $3 \mu \mathrm{m}$ \\
Rise time & $124 \pm 4 \mathrm{~ms}$ \\
Poisson's ratio & 0.35 \\
Test temperature & $20^{\circ} \mathrm{C}$ \\
Specimen thickness & $40-80 \mathrm{~mm}$ \\
\hline
\end{tabular}

\subsection{Repeated Load Axial Test (RLAT)}

In the UK, the RLAT is the most widely used standard mechanical test for assessing the permanent deformation characteristics of bituminous mixtures. The test applies a repeated pulse load to simulate traffic and measures the permanent deformation after each repeated load. The protocol for the RLAT test was performed based on BS EN 12697-25. Table 4 shows the test configuration [29]. After compaction, the specimens were cured at $20^{\circ} \mathrm{C}$ for 28 days; after that they were cured in a forced draft oven for a further of 7 days at $40^{\circ} \mathrm{C}$. This curing protocol was selected to ensure that a fully cured condition was achieved, as recommended by Needham [9] and Oke [30]. The two faces of the specimen were coated with a thin layer of silicone grease with graphite powder before running the test. Graphite powder is used to eliminate the influence of unevenness of the specimen face on the test results. 
Table 4. RLAT test configuration based on BS EN 12697-25

\begin{tabular}{ll}
\hline Item & Range \\
\hline Specimen diameter & $100 \pm 2 \mathrm{~mm}$ \\
Conditioning stress & $10 \mathrm{kPa}$ \\
Conditioning period & $600 \mathrm{~s}$ \\
Test stress & $100 \mathrm{kPa}$ \\
Test Duration & 3600 cycles \\
Test Cycle & Square wave pulses $1 \mathrm{~s}$ on, 1s off \\
Specimen thickness & $40-80 \mathrm{~mm}$ \\
Test temperature & $40^{\circ} \mathrm{C}$ \\
\hline
\end{tabular}

\subsection{Durability tests}

Durability is a feature directly related to the effect of environmental conditions on the performance of asphalt mixtures during their service life. The durability of CAEMs was evaluated against both moisture and frost damage. This was to present a wide overview regarding the performance of CAEMs in warm and cold climates. Both damage modes are considered as potentially serious problems in a climate such as in the UK. They were evaluated based on BS EN 12697-12 [31] and AASHTO T283 [32], respectively as presented in Table 5.

Table 5. Summary of durability test protocols used

\begin{tabular}{ccc}
\hline & $\begin{array}{c}\text { Moisture damage } \\
\text { (BS EN 12697-12) }\end{array}$ & $\begin{array}{c}\text { Frost damage } \\
\text { (AASHTO T283) }\end{array}$ \\
\hline Unconditioned sets & Curing for 7 days at $20^{\circ} \mathrm{C}$ & Curing for 7 days at $20^{\circ} \mathrm{C}$ \\
& Curing for 7 days at $20^{\circ} \mathrm{C}+$ & Curing for 7 days at $20^{\circ} \mathrm{C}+$ Vacuum \\
Conditioned sets & $\begin{array}{c}\text { Vacuum saturation at } 6.75 \mathrm{kPa} \text { for } \\
\text { 30mins }+ \text { Soaking for } 3 \text { days at } \\
\text { for } 16 \mathrm{hrs} \text { at }-18^{\circ} \mathrm{C}+\text { Thawing } 24 \mathrm{hrs} \\
\text { at } 60^{\circ} \mathrm{C}+2 \mathrm{hrs} \text { at } 20^{\circ} \mathrm{C}\end{array}$ \\
\hline
\end{tabular}

The durability of asphalt mixtures can be defined by the loss of strength due to the impact of the exposure conditions. The evaluation of durability was determined as a ratio of the indirect tensile strength (ITS) of conditioned specimens to those of unconditioned specimens, expressed in percent (\%). The ITS test involved applying a diametric compression load with a constant deformation rate of $(50 \pm 2) \mathrm{mm} / \mathrm{min}$ on the samples between two uniform loading strips. This enables tensile stresses to develop along the diametric vertical plane to cause a splitting failure. The test was conducted at $20^{\circ} \mathrm{C}$ using Instron test equipment. 


\subsection{Mineralogy and microstructure tests}

X-ray diffraction analysis was utilised to study the hydration of blended cementitious materials and the mineralogical patterns of the crystalline solids within the CAEMs. After 28 days of curing at $20^{\circ} \mathrm{C}, \mathrm{CAEM}$ specimens were crushed into small parts. For XRD examination, some of these parts (from the middle of the specimens) were ground to a powder and passed through a $63 \mu \mathrm{m}$ sieve. The grinding process was continued until all parts passed through the sieve. This was to detect all the crystalline hydration phases in the XRD patterns. The powder samples were positioned and flattened carefully in the sample holder of the XRD machine. A scanning speed of $2^{\circ}$ per minute and a step of $0.02^{\circ}$ were used in the range of 10 to $60^{\circ}$ using a Bruker $-\mathrm{AXS}$ D8 Advance XRD equipment. For examining the morphology and the internal microstructure (the associated changes to the hydration products due to the use of binary and ternary blended fillers in CAEMs), other pieces were fixed on small SEM stubs and exposed to high vacuum. Then, a platinum coating was applied to the fractured specimen before capturing the SEM images (secondary electron mode) using a Philips XL 30 SEM instrument. Fig. 3 summarizes the methodology to investigate the internal microstructure of CAEM.

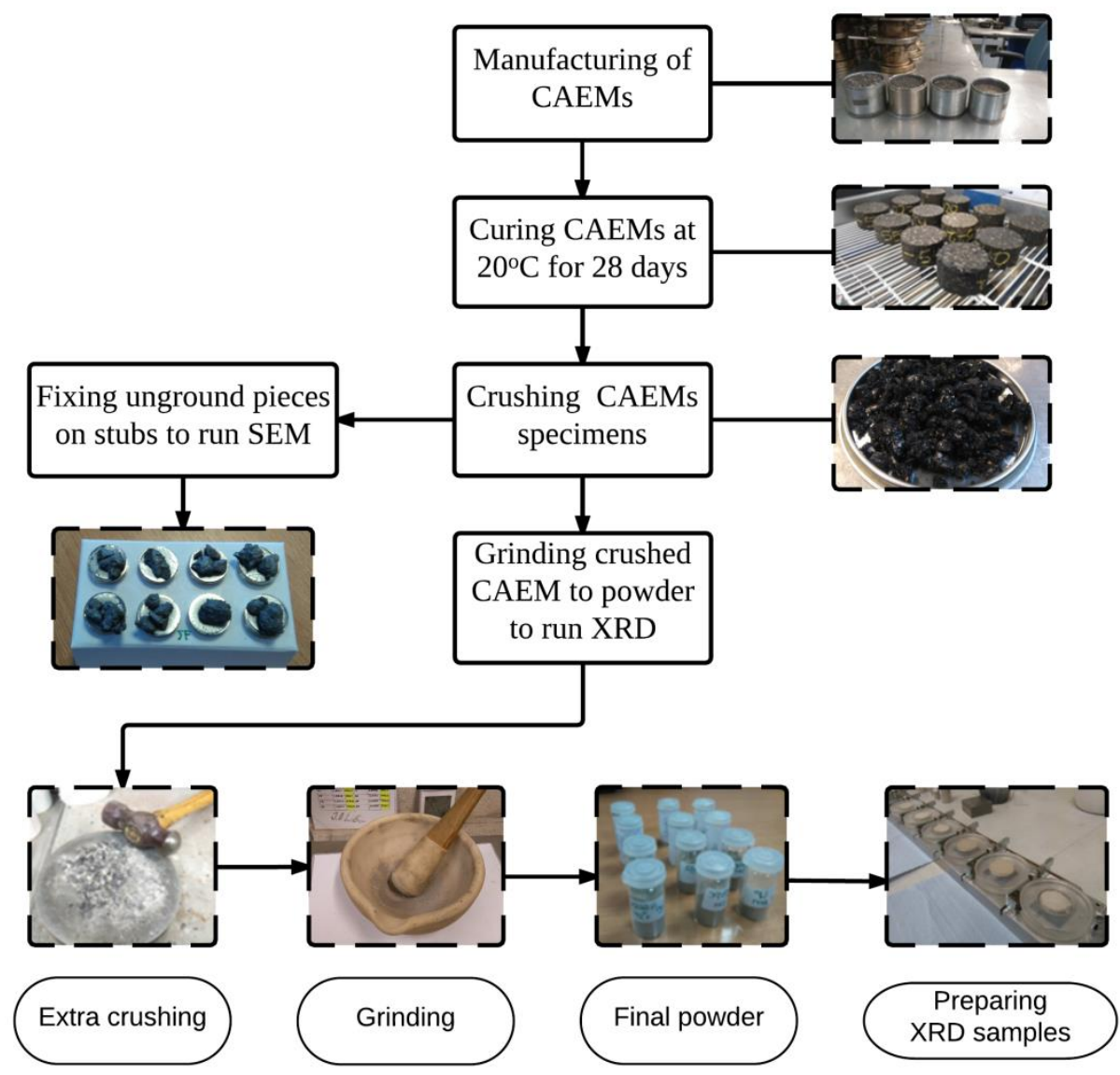

Fig. 3. Methodology to investigate the internal microstructure of CAEM 


\section{Results and discussion}

\subsection{Indirect Tensile Stiffness Modulus}

Fig. 4 presents the average stiffness modulus of CAEMs for three specimens for each mix with a maximum and minimum coefficient of variation of $13.06 \%$ and $0.94 \%$, respectively. It can be observed that the stiffness modulus differences are markedly increased when either BBF or TBF has replaced the conventional filler in the LF-mix. In CAEMs containing TBF, stiffness modulus is generally higher than in those with BBF, indicating a positive effect of adding SF, see section 5.5. However, SF addition improved the stiffness of the mixes containing FA much more than those containing GGBS. The values of stiffness modulus for TBF treated CAEMs are only slightly lower than those for the OPC-mix, indicating the positive effect of this kind of cement replacement.

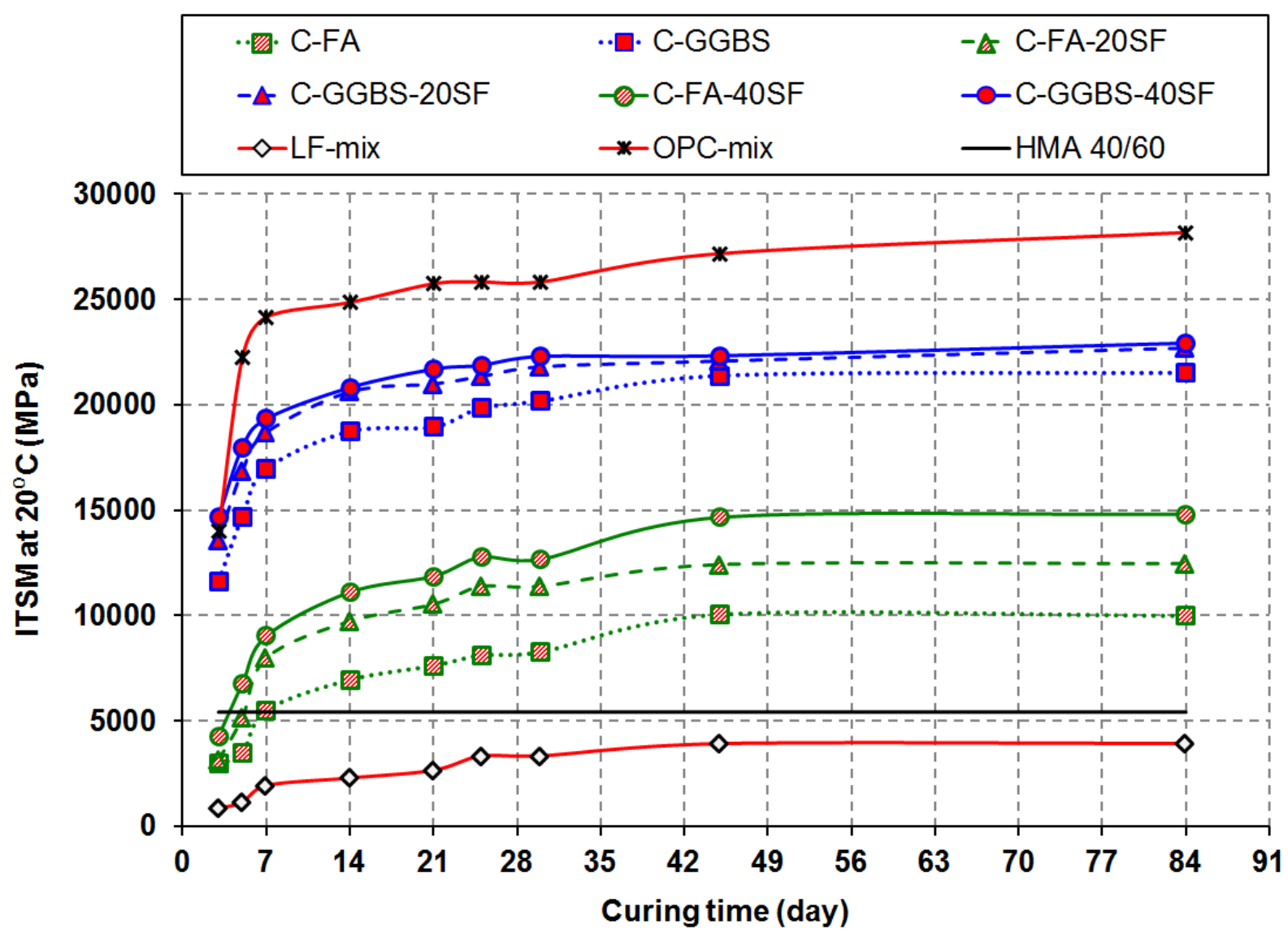

Fig. 4. The stiffness modulus development of studied mixtures 
Low early stiffness is one of the main drawbacks of cold asphalt mix containing LF, as is clear in Fig. 4. However, a remarkable stiffness increase was achieved within only one week of curing using both BBF and TBF. The obtained stiffness for these mixes can contribute effectively to minimizing the curing time in the field. For example, the early stiffness of C-FA, C-FA-20SF and C-FA-40SF are approximately 3 to 5 times higher than untreated LF-mix, and these become 13 to 17 times in C-GGBS, C-GGBS-20SF and C-GGBS-40SF mixes during the first week. These results might be attributed to the pozzolanic reaction caused by FA, GGBS and SF in combination with low cement content to produce another hydraulic binder (see section 5.5). These findings are consistent to those obtained by Al-Busaltan, Al Nageim, Atherton and Sharples [6] and Al-Hdabi, Al Nageim, Ruddock and Seton [7]. However, the stiffness values were much higher than those found by Al-Busaltan, Al Nageim, Atherton and Sharples [6] and Al-Hdabi, Al Nageim, Ruddock and Seton [7]. This might be related to different factors such as the aggregate type, bitumen emulsion content and compaction method.

The results also demonstrated that the HMA 40/60 mix did not show any stiffness development during the curing period. The stiffness of this mix was constant from an age of 3 days until the end of the curing period. In comparison, the stiffness modulus of HMA 40/60 (5400 MPa) was surpassed by the OPC-mix and all the CAEMs including GGBS within the first three days. CFA, C-FA-20SF and C-FA-40SF mixes achieved this value after 5-7 days whereas the untreated LF-mix never reached this stiffness value during the curing period. The stiffness of the blended mixes could, therefore, lead to reduced curing time in the field.

It is worth mentioning that the air voids of the treated CAEMs varied between $8.50 \%$ for OPCmix to $10.30 \%$ for C-GGBS-40SF. However, the control LF-mix had 10.34\%. The results demonstrate an improvement of volumetric properties for treated CAEMs which may affect positively on their performance. This improvement will be discussed later in section 5.5.

\subsection{The effect of temperature on stiffness modulus}

Stiffness modulus of CAEMs after 28 days of curing was evaluated at different testing temperatures, namely 5, 20 and $40^{\circ} \mathrm{C}$, as shown in Fig. 5. The stiffness modulus decreased with the increase of temperature. This trend is very strong in both HMA 40/60 and LF-mix. However, in treated CAEMs, the reduction in the stiffness depends on the type of filler. For example, stiffness reductions of only $28 \%$ and $43 \%$ resulted when heating C-GGBS and C-FA-40SF respectively from 5 to $40^{\circ} \mathrm{C}$. In contrast, HMA 40/60 and LF-mix lost 95-98\% of their stiffness 
under the same condition. This might be considered as an excellent advantage in terms of the pavement performance in hot weather. This could potentially make the asphalt material less prone to cracking at low temperatures and less prone to rutting at high temperatures. These results are comparable to those published by other authors $[14,33,34]$.

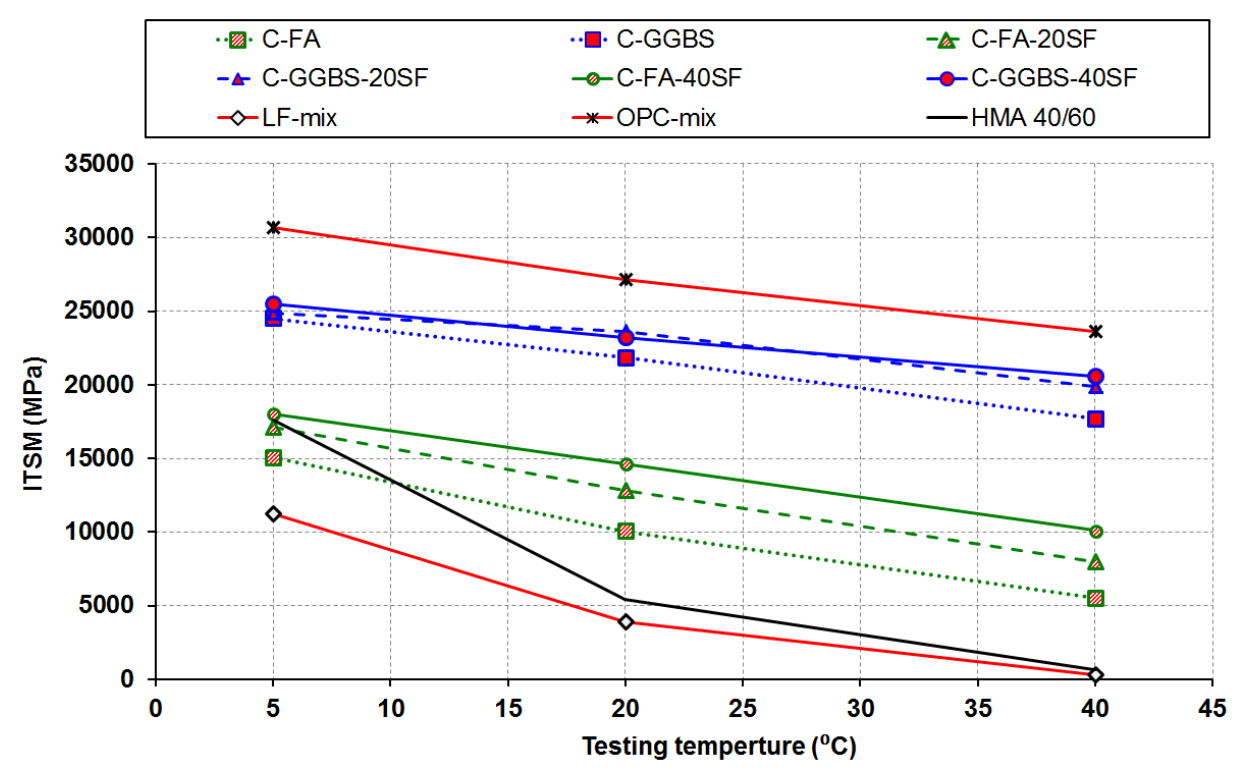

Fig. 5. Stiffness modulus under different testing temperatures

\subsection{Resistance to permanent deformation}

The results of the repeated load axial test are shown in Fig. 6 while the creep modulus of CAEMs and the percentage reduction in permanent strain relative to the LF-mix are displayed in Fig. 7.

\begin{tabular}{|c|c|c|}
\hline ・四・C-FA & $\because \square \cdot C-G G B S$ & $-\Delta C-F A-20 S F$ \\
\hline$\triangle-\mathrm{C}-\mathrm{GGBS}-20 \mathrm{SF}$ & $\rightarrow C-F A-40 S F$ & $\rightarrow$ C-GGBS-40SF \\
\hline$\diamond$ LF-mix & $\rightarrow$-OPC-mix & - HMA 40/60 \\
\hline
\end{tabular}

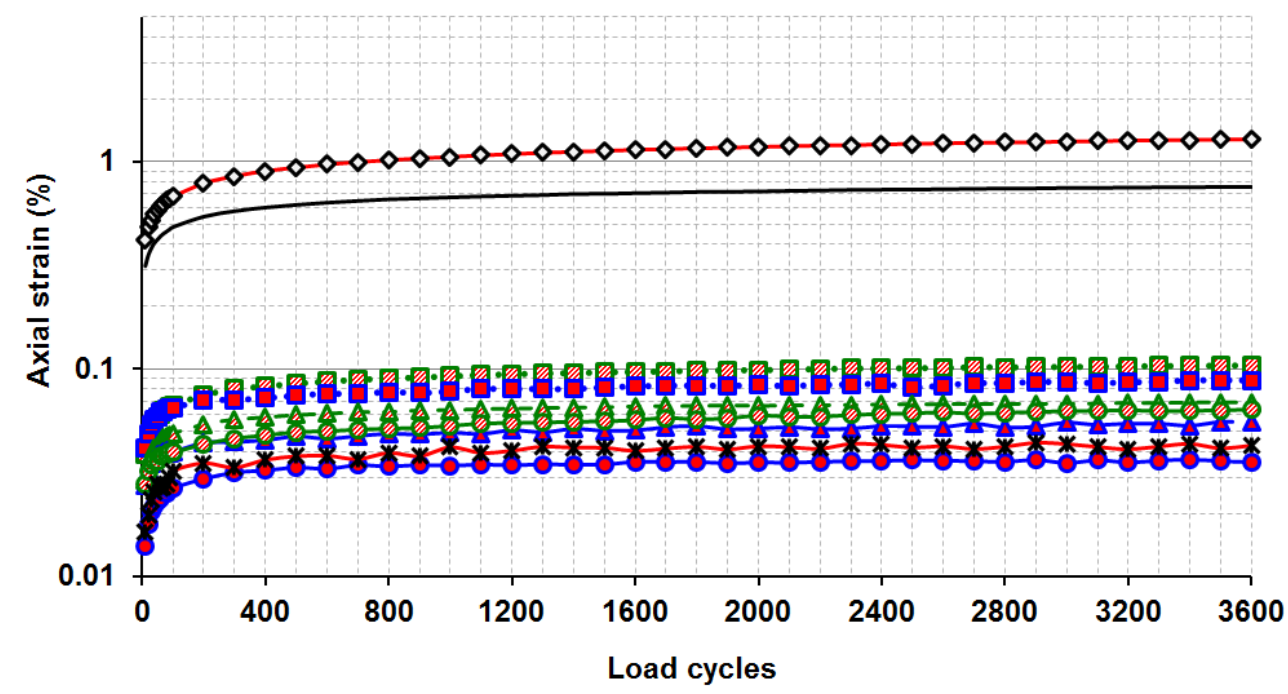


Fig. 6. The permanent strain in CAEMs under 100kPa stress

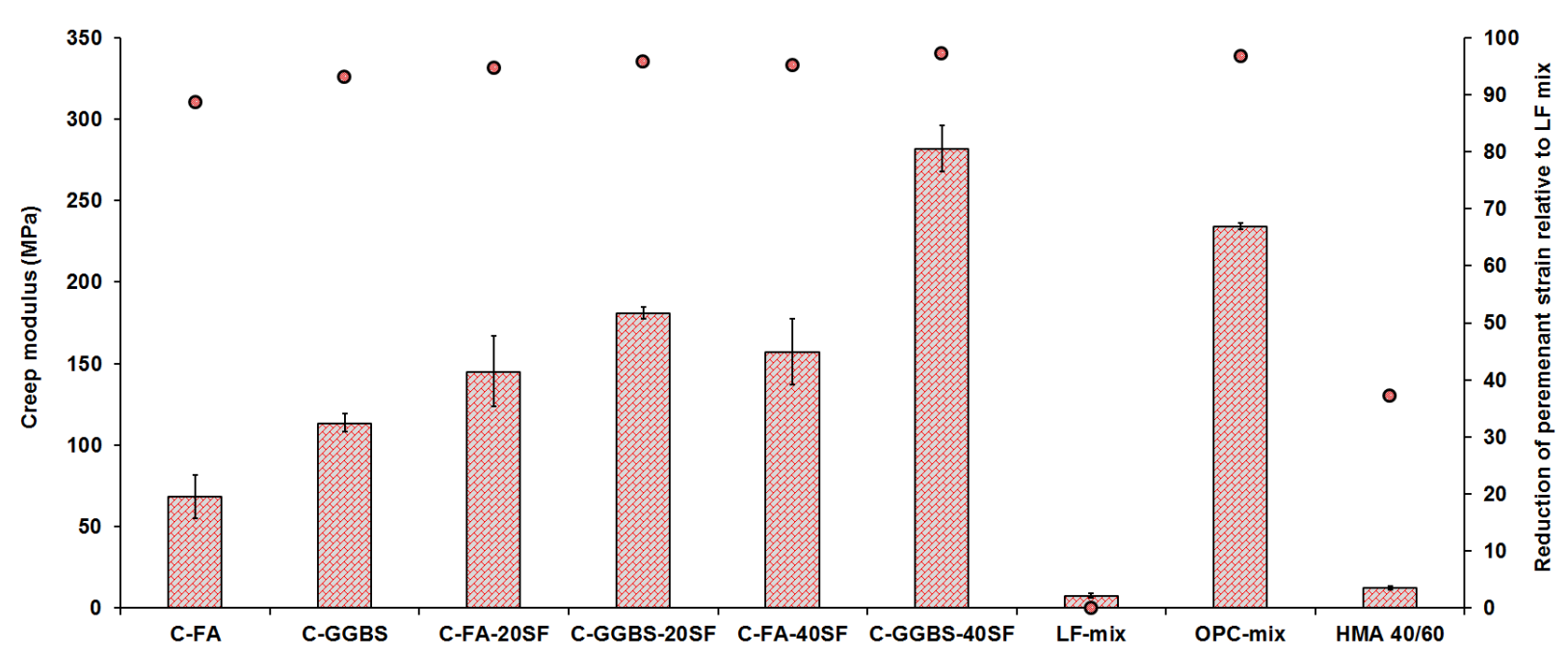

Fig. 7. The creep stiffness modulus of CAEMs and the percentage of reduction in permanent strain

The results, in Fig. 6, show that the incorporation of BBF and TBF resulted in a remarkable decrease in the permanent strains relative to the untreated LF-mix and HMA 40/60. These two mixes exhibited much higher strain values throughout the test. In mixtures containing BBF, the use of this type of filler combination resulted in a reduction in a permanent strain of 89-93\% relative to the LF-mix while the reduction was about 95-97\% for mixtures containing TBF, see Fig. 7.

The maximum achieved values of creep stiffness modulus (181.3 and 282.1 MPa) were recorded for the CAEM mix containing TBF (OPC plus GBBS) with $20 \% \mathrm{SF}$ and $40 \% \mathrm{SF}$ additions respectively as shown in Fig. 7. This may be attributed to the ability of GGBS mixtures to maintain a higher amount of trapped water inside the mixture in comparison to FA replacement [35]. This is more likely to enhance the hydration of cement. More interestingly, the resistance to permanent deformation for the C-GGBS-40SF mix is quite high compared to OPC-mix. This also might be related to the role of highly densified SF in producing a dense microstructure, particularly with the GGBS combination. Overall, it can be concluded that CAEMs treated with BBF and TBF have significantly decreased susceptibility to permanent deformation, indicating the potential benefit of using this material on heavily trafficked roads. 


\subsection{Durability against moisture and frost damage}

Fig. 8 illustrates the ITS test results in both conditioned and unconditioned states (see Table 5). From this figure, the possible benefits gained from incorporating BBF and TBF fillers into CAEMs are clear.

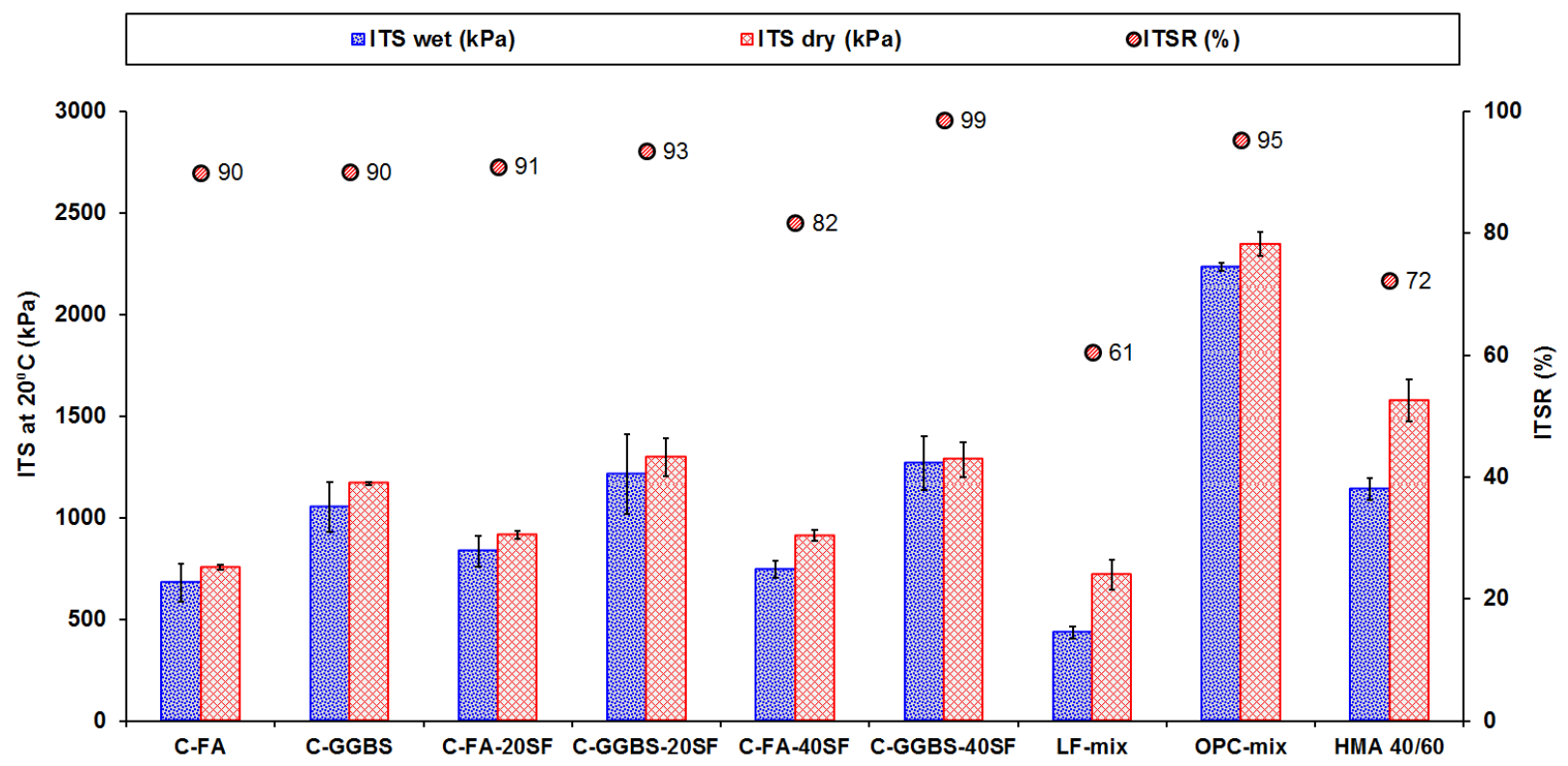

Fig. 8. The results of moisture damage for CAEMs

The ITSR values (ratios of wet to dry ITS) of treated CAEMs (with BBF and TBF) were higher than that for the untreated LF-mix and the equivalent HMA (HMA 40/60). Moreover, these values were comparable with the OPC-mix. These higher values of ITSR (the ability of the mix to maintain its strength after damage) may be related to the formation of new hydration products due to the incorporation of pozzolanic materials with cement. In addition, the temperature rises due to heating which would accelerate the hydration process of these active fillers. The results are consistent with trends noticed in concrete $[36,37]$. This leads to the conclusion that CAEMs with these multi-blended fillers are less susceptible to moisture damage.

The ITS values before and after exposure to freeze-thaw cycles and corresponding ITSR values are shown in Fig. 9. Overall, the trend of the results is approximately similar to those of moisture damage presented in Fig. 8. It can be seen that the ITSR values of HMA 40/60 and CAEMs treated with $\mathrm{BBF}, \mathrm{TBF}$ and $5 \%$ of OPC are in the range from $77 \%$ to $105 \%$. However, LF-mix shows lower ITSR value of 53\%. Thus, it can be concluded that incorporating waste by-product fillers had a significant positive effect on making CAEMs less susceptible to frost damage and 
stripping problems. Furthermore, the C-GGBS-40SF mix showed the highest resistance to exposure to both moisture and freeze-thaw damage which might be attributed to the same reason suggested in the discussion relating to Fig. 4. Further, it should be noted here that the microstructural evaluation in section 5.5 supported the positive impact of adding the (OPC+GGBS and SF) on the internal structure of TBF-CAEMs.

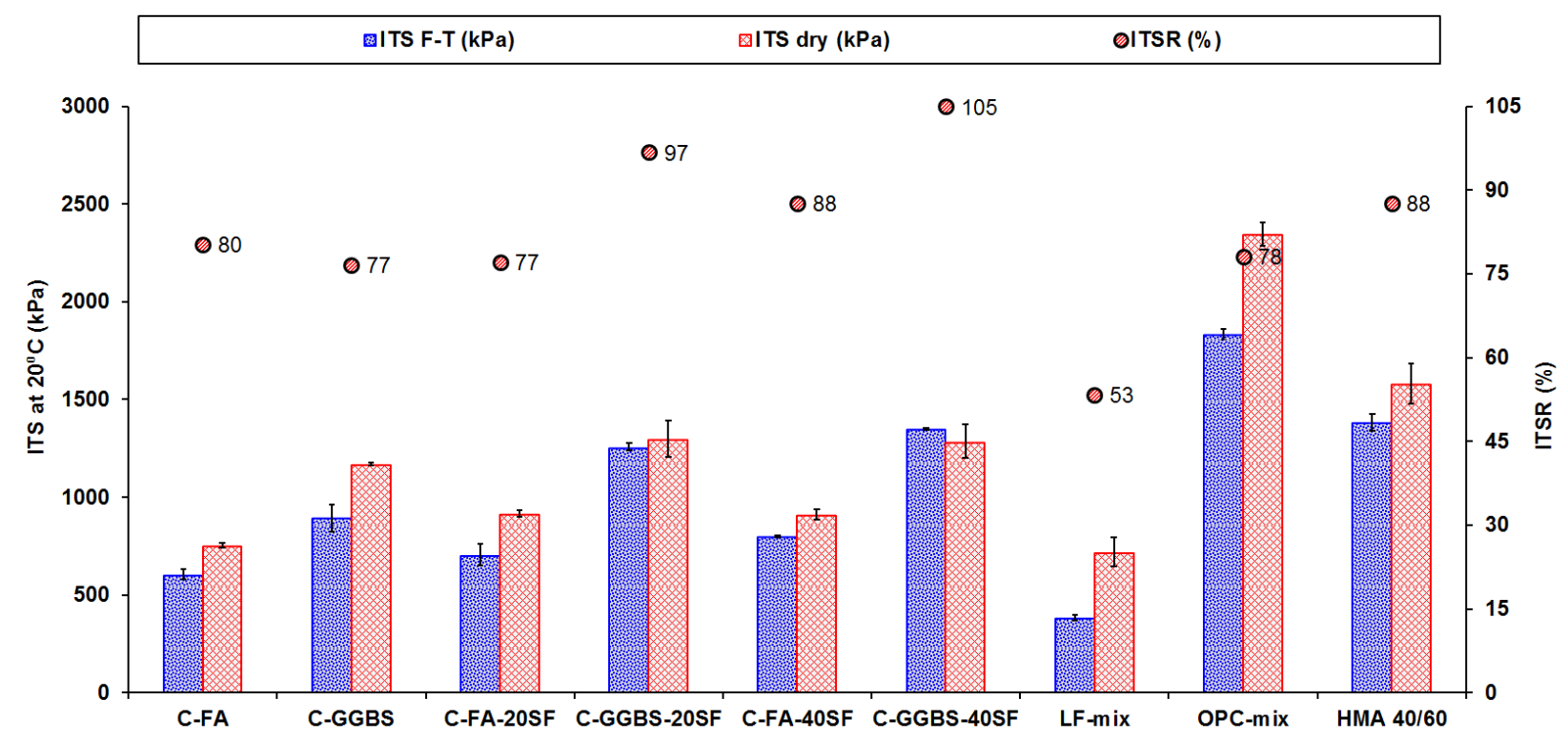

Fig. 9. The results of frost damage for CAEMs

There is no universally accepted minimum level of ITSR to define a CAEM as a durable material for structural purposes in a pavement exposed to severe conditions. However, the authors would suggest that CAEM should be considered a sufficiently durable material against moisture and frost damage if the values of ITSR for both types of damage are more than $70 \%$. A similar suggestion of minimum acceptable ITSR is found in the literature for HMA [38, 39]. Under this proposed criterion, all the produced CAEMs in the present study are relatively resistant to moisture and frost damage except the untreated LF-mix.

\subsection{XRD analysis and SEM examination}

Fig. 10 shows the XRD patterns for CAEM mixtures while Fig. 11 illustrates the morphology of their internal microstructure in detail.

The XRD analysis demonstrated a presence of $\mathrm{Ca}(\mathrm{OH})_{2}$ (Portlandite) with a high reference intensity peak in the OPC-mix indicating a lower degree of hydration compared to binary and ternary CAEMs. The $\mathrm{Ca}(\mathrm{OH})_{2}$ in all the inspected specimens was identified by a reference 
intensity peak at $34.1^{\circ} 2$-theta scale [40]. The intensity values at $34.1^{\circ}$ were reduced significantly in each C-GGBS, C-FA, C-GGBS-40SF and C-FA-40SF compared to OPC-mix. This reduction might be explained by the reaction of $\mathrm{Ca}(\mathrm{OH})_{2}$ with pozzolanic materials. Another potential reason is that BBFs and TBFs, which contain low cement content, lead to reduce the $\mathrm{Ca}(\mathrm{OH})_{2}$ availability. Overall, these results demonstrate a reduction in the concentration of undesired hydration products such as large crystals of $\left.\mathrm{Ca}(\mathrm{OH})_{2}\right)$.

However, SEM examination (Fig. 11e) demonstrated a tiny presence of hexagonal crystals of $\mathrm{Ca}(\mathrm{OH})_{2}$ compound in the BBF-FA mixture. The absence of this compound in the XRD pattern of the reference LF-mix is not an indicator of a higher degree of hydration, but it is certainly due to the absence of cement in this mixture. The higher degree of hydration obtained in the BBF and TBF mixtures as deduced from XRD patterns and SEM observations led to enhancement of most engineering features. This might be as a result of the pozzolanic activity of the FA, GGBS and the very high reactivity of SF. Active fillers and mineral admixtures can efficiently consume the $\mathrm{Ca}(\mathrm{OH})_{2}$ phase in the cement matrix and produce a higher degree of hydration and dense internal microstructure with less porosity. This might be achieved by producing an additional $\mathrm{CSH}$ (cement gel) in the presence of water. Both $\mathrm{Ca} / \mathrm{Si}$ ratio and the available water molecules in the new CSH products might give different features compared to the original CSH hydration product [37]. However, the growth and development of the hydration products in CAEMs, due to the presence of bitumen emulsion, might differ from those of pure cement or cement-filler matrices [18]. Thus, it would be interesting to identify the changes in the formation of the hydration products in CAEMs as well as these due to the addition of active fillers in these mixtures.

From this perspective and for a pure cement-bitumen matrix, the SEM examination in Fig. 11a-d suggested that the presence of the bitumen might not affect the hydration of the silicates in cement. The formation of additional $\mathrm{CSH}$ was observed due to the replacement of conventional LF by cement and active fillers. However, it seems that it can cause a delay in the formation of other hydration products (Ettringite) resulted from the hydration of aluminates in cement (as shown in Fig. 11d). Further research is needed to explain the change in cement hydration mechanism in the presence of bitumen more deeply. 

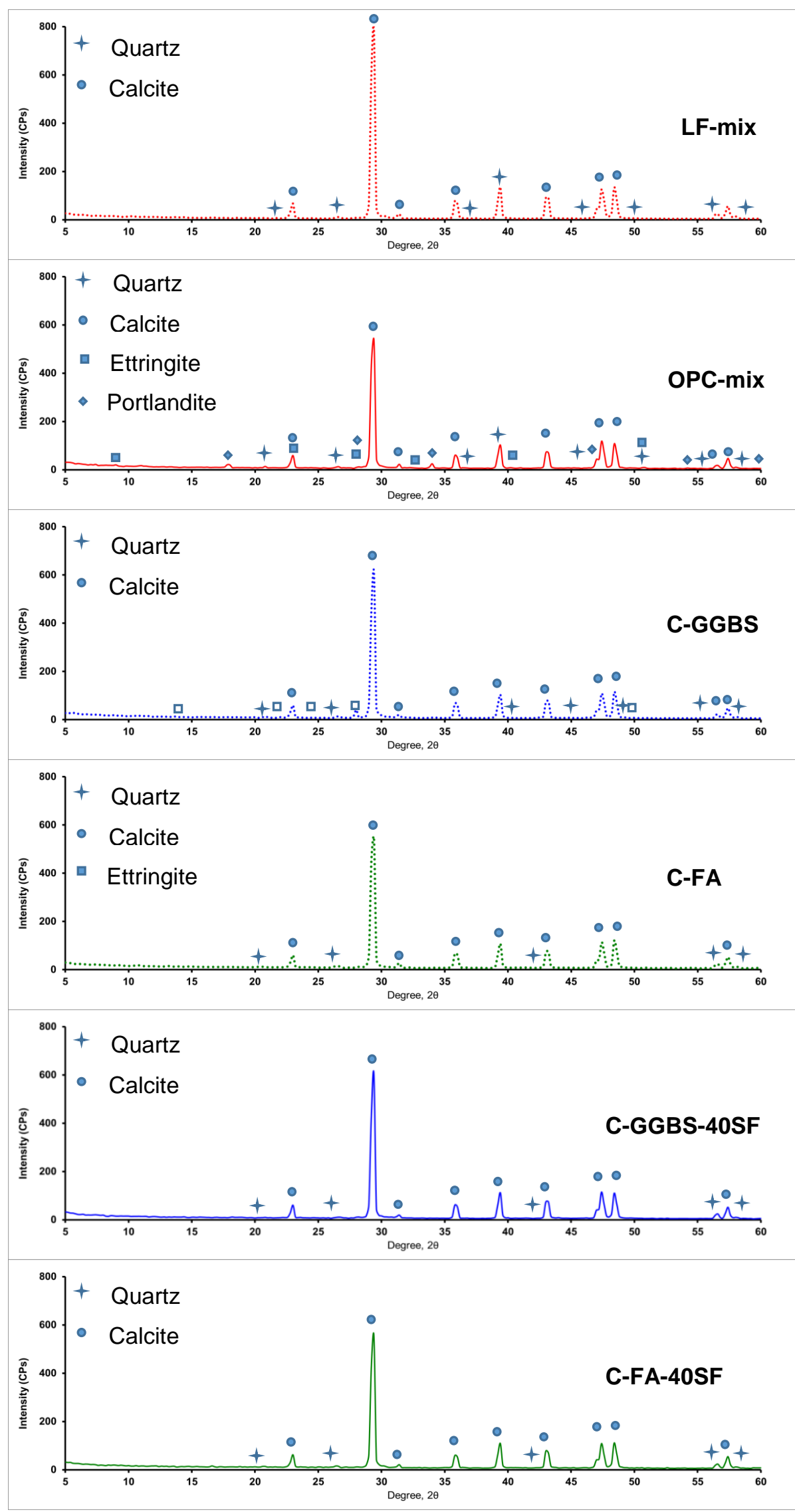

Fig. 10. XRD results of CAEMs 
The SEM examination (Fig. 11c, d and e) showed that, even after 28 days of curing, the presence of Ettringite with needle shape (AFt) was clearly observed in many places in the binary blended matrices. This is especially in the capillary voids of the FA-BBF mixture, in contrast to the reference LF-mix and OPC-mix. The presence of the AFt phase at later ages indicates to a delayed reaction, and the resulting AFt phase is not an expansive hydration phase at ambient temperature [41]. Thus, it can improve the volumetric properties (less porosity) of the CAEM by minimising both the pore sizes and their continuity, see section 5.1. This consequently inhibits the movement of water and other types of aggressive fluid into the mixture and can thus effectively improve the durability of cold asphalt mixtures.

However, when exposed to heat due to hot/warm weather in the presence of water, AFt transforms to the second expansive form which is monosulfate with prismatic shape (AFm). This form had an increase of 2.3 times in volume [41]. The formation of internal stresses inside the capillary pores of the bitumen-cement matrix due to this volume increase and the susceptibility of AFt to dissolve in the presence of water might be a potential reason for less durable mixtures. 

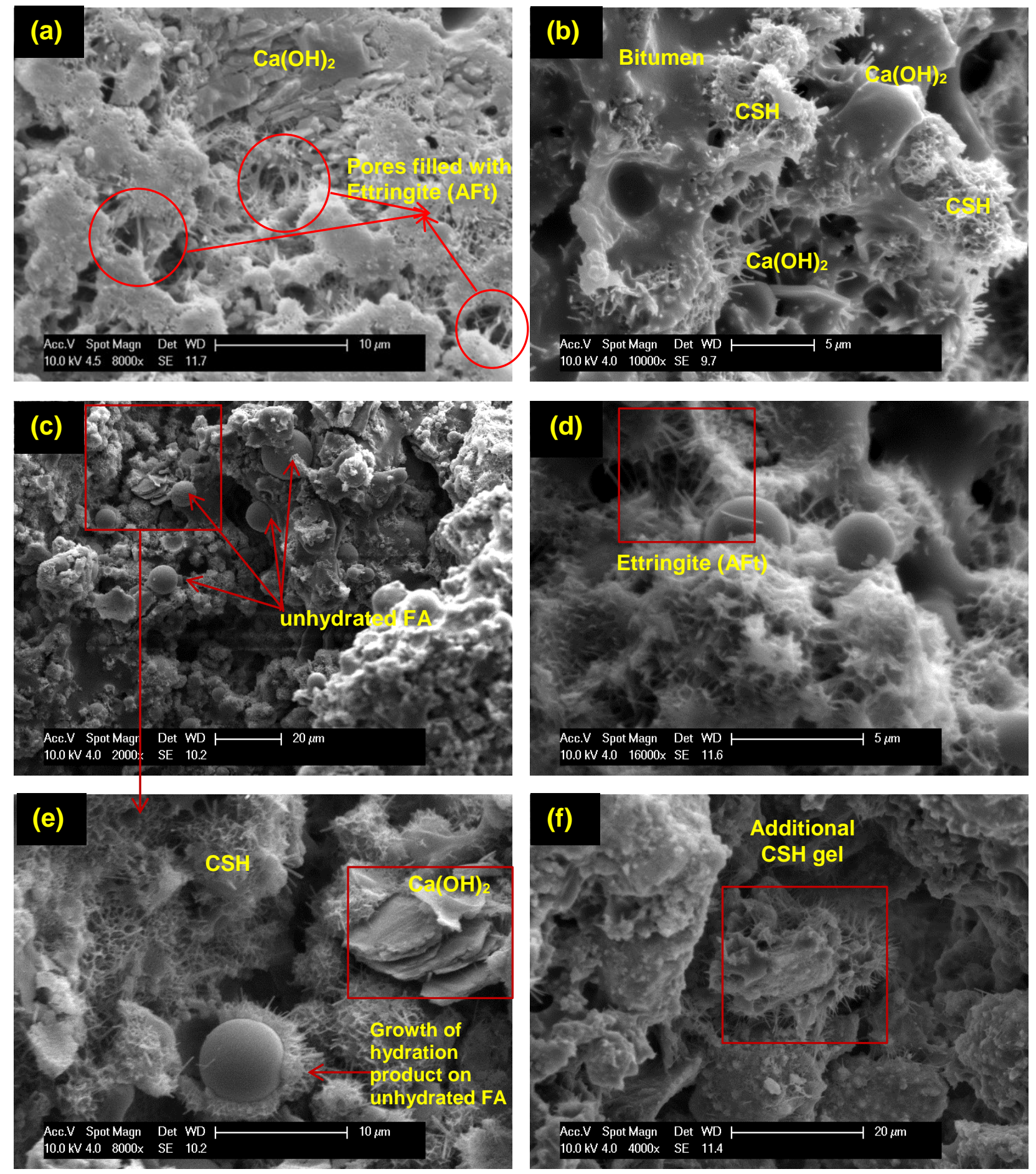

Fig. 11. Morphology details of the microstructure of CAEMs: (a) and (b) morphology of OPC-mix, (c) morphology of BBF mixture (C-FA) at low magnification, (d) and (e) morphology of BBF mixture (C-FA) at high magnification and (f) additional hydration products formation in TBF mixture (C-GGBS-40SF) 
The SEM observation indicated that the deposition of AFt phase inside the capillary pores was more pronounced in the FA binary mixture in comparison with GGBS. However, it completely disappeared in the presence of SF addition for the TBF mixtures (both FA and GGBS). Instead, a more CSH gel formation was deduced as shown in Fig. 11f. Compared to other CAEMs, a very

high intensity of the reference peak of $\mathrm{CaCO}_{3}$ (calcite) was detected in the XRD pattern for the LF-mix (Fig. 10). This might indicate the non-reactivity of this filler and its inability to enhance the internal microstructure and chemical composition as the microstructural observation revealed. The low values obtained for most of these properties for the LF-mix, as presented previously, might support this hypothesis.

\section{Conclusions}

The current work aimed to investigate the impact of incorporating binary and ternary blended fillers (BBF and TBF) on both the engineering and microstructure properties of cold asphalt emulsion mixtures (CAEMs). The conclusions of the study can be summarized as follows:

- Significant enhancements were obtained in engineering properties due to the incorporation of by-product fillers, ground granulated blast furnace slag (GGBS) and fly ash (FA), in combination with cement in BBF mixtures, while further substantial improvements of such features were achieved by adding silica fume (SF) for TBF mixtures.

- The impact of the temperature increase, from 5 to $40^{\circ} \mathrm{C}$, on the stiffness modulus was much greater in HMA 40/60 and LF-mix than in the other CAEMs investigated. After heating to $40^{\circ} \mathrm{C}$, stiffness reduced by $96 \%$ and $93 \%$ for HMA $40 / 60$ and LF-mix respectively whereas reductions of $28 \%$ and $43 \%$ were recorded for the BBF mix with GGBS and TBF with FA-40SF, respectively.

- The replacement of LF with TBF $(\mathrm{OPC}+\mathrm{GGBS}+\mathrm{SF})$ showed lower axial strain than the other type of $\mathrm{TBF}(\mathrm{OPC}+\mathrm{FA}+\mathrm{SF})$ in the repeated load axial test.

- Treatment of CAEMs with BBF and TBF significantly decreased its susceptibility to permanent deformation by producing higher creep stiffness modulus, indicating the potential benefit of using this material on heavily trafficked roads. The maximum creep stiffness modulus was achieved in the TBF with both GGBS and SF. 
- All the CAEMs produced in the present study were considered to be durable as the control hot mix (HMA 40/60) except the LF-mix; maintaining more than $70 \%$ of their strength after exposure to both moisture and frost damage.

- The combined results of stiffness modulus and the mineralogical and microstructural assessments suggested that the SF addition to BBF- CAEMs can eliminate any delay in hydration product formation (aluminates in cement) caused by bitumen emulsion in the CAEMs. However, the effect on the other hydration products (silicates in cement) might be much close to the pure cement matrix without bitumen emulsion.

- Further investigations are needed to examine the hydration products in CAEM at nanoscale to understand the effect or presence bitumen emulsion on the structure of hydration products.

\section{Acknowledgments}

The authors would like to acknowledge the University of Nottingham which has funded this research through the Dean of Engineering Research Scholarship for International Excellence. Furthermore, the authors wish to express their sincere gratitude to the technicians of the Nottingham Transportation Engineering Centre at the University of Nottingham for their kind support and assistance. The authors also wish to thank Dr. Nigel Neate (University of Nottingham - Faculty of Engineering) for his help in conducting the XRD and SEM tests. The authors gratefully acknowledge the valuable support of Nynas and Hanson for providing the bitumen emulsions and slag, respectively. 


\section{References}

[1] A. Modarres, P. Ayar, Comparing the mechanical properties of cold recycled mixture containing coal waste additive and ordinary Portland cement, International Journal of Pavement Engineering (ahead-of-print) (2014) 1-14.

[2] M. Pasetto, N. Baldo, Experimental evaluation of high performance base course and road base asphalt concrete with electric arc furnace steel slags, Journal of Hazardous Materials 181(1) (2010) 938-948.

[3] I. Pérez, L. Medina, M.Á. del Val, Mechanical properties and behaviour of in situ materials which are stabilised with bitumen emulsion, Road Materials and Pavement Design 14(2) (2013) 221-238.

[4] B. Gómez-Meijide, I. Pérez, Effects of the use of construction and demolition waste aggregates in cold asphalt mixtures, Construction and Building Materials 51(0) (2014) 267-277.

[5] B. Gómez-Meijide, I. Pérez, G. Airey, N. Thom, Stiffness of cold asphalt mixtures with recycled aggregates from construction and demolition waste, Construction and Building Materials 77(0) (2015) 168-178.

[6] S. Al-Busaltan, H. Al Nageim, W. Atherton, G. Sharples, Mechanical Properties of an Upgrading Cold-Mix Asphalt Using Waste Materials, Journal of Materials in Civil Engineering 24(12) (2012) 1484-1491.

[7] A. Al-Hdabi, H. Al Nageim, F. Ruddock, L. Seton, Development of Sustainable Cold Rolled Surface Course Asphalt Mixtures Using Waste Fly Ash and Silica Fume, Journal of Materials in Civil Engineering 26(3) (2013) 536-543.

[8] G. Betti, G. Airey, K. Jenkins, A. Marradi, G. Tebaldi, Active Filler's Effect on In Situ Performances of Bitumen Emulsion Recycled Mixtures, 8th RILEM International Symposium on Testing and Characterization of Sustainable and Innovative Bituminous Materials, Springer, 2016, pp. 799-810.

[9] D. Needham, Developments in bitumen emulsion mixtures for roads, University of Nottingham, UK, 1996.

[10] I.N.A. Thanaya, S. Zoorob, J. Forth, A laboratory study on cold-mix, cold-lay emulsion mixtures, Proceedings of the ICE-Transport 162(1) (2009) 47-55.

[11] Y.-R. Kim, J.S. Lutif, A. Bhasin, D.N. Little, Evaluation of moisture damage mechanisms and effects of hydrated lime in asphalt mixtures through measurements of mixture component properties and performance testing, Journal of Materials in Civil Engineering 20(10) (2008) 659667.

[12] Y.-R. Kim, D. Little, I. Song, Effect of mineral fillers on fatigue resistance and fundamental material characteristics: mechanistic evaluation, Transportation Research Record: Journal of the Transportation Research Board (1832) (2003) 1-8.

[13] S. Oruc, F. Celik, M.V. Akpinar, Effect of cement on emulsified asphalt mixtures, Journal of Materials Engineering and Performance 16(5) (2007) 578-583.

[14] M. Bocci, A. Grilli, F. Cardone, A. Graziani, A study on the mechanical behaviour of cement-bitumen treated materials, Construction and Building Materials 25(2) (2011) 773-778.

[15] A. Al-Hdabi, H. Al Nageim, F. Ruddock, L. Seton, Laboratory studies to investigate the properties of novel cold-rolled asphalt containing cement and waste bottom ash, Road Materials and Pavement Design 15(1) (2014) 78-89.

[16] S. Du, Performance Characteristic of Cold Recycled Mixture with Asphalt Emulsion and Chemical Additives, Advances in Materials Science and Engineering Volume 2015 (2015).

[17] N. Pouliot, J. Marchand, M. Pigeon, Hydration mechanisms, microstructure, and mechanical properties of mortars prepared with mixed binder cement slurry-asphalt emulsion, Journal of Materials in Civil Engineering 15(1) (2003) 54-59.

[18] S. Du, Interaction mechanism of cement and asphalt emulsion in asphalt emulsion mixtures, Materials and Structures 47(7) (2014) 1149-1159. 
[19] Z. Wang, X. Shu, T. Rutherford, B. Huang, D. Clarke, Effects of asphalt emulsion on properties of fresh cement emulsified asphalt mortar, Construction and Building Materials 75 (2015) 25-30.

[20] X. Fang, A. Garcia, F. Winnefeld, M.N. Partl, P. Lura, Impact of rapid-hardening cements on mechanical properties of Cement Bitumen Emulsion Asphalt, Materials and Structures (2014) 1-12.

[21] European Committee for Standarization, BS EN 13108-1 Bituminous Mixtures- Material Specifications, Part 1: Asphalt Concrete British Standards Institution, London, UK, 2006.

[22] A. Nikolaides, A New Design Method for Dense Cold Mixtures, The First European Symposium on Performance and Durability of Bituminous Materials, University of Leeds, UK, 1994, p. 259.

[23] I.N.A. Thanaya, Improving the performance of cold bituminous emulsion mixtures (CBEMs): incorporating waste, University of Leeds, UK, 2003.

[24] A.I. Nassar, N. Thom, T. Parry, Optimizing the mix design of cold bitumen emulsion mixtures using response surface methodology, Construction and Building Materials 104 (2016) 216-229.

[25] C. Ojum, K. Kuna, N.H. Thom, G. Airey, An investigation into the effects of accelerated curing on Cold Recycled Bituminous Mixes, International Conference on Asphalt Pavements, ISAP 2014, pp. 1177-1188.

[26] H.A. Khalid, O.K. Monney, Moisture damage potential of cold asphalt, International Journal of Pavement Engineering 10(5) (2009) 311-318.

[27] J.-P. Serfass, J.-E. Poirier, J.-P. Henrat, X. Carbonneau, Influence of curing on cold mix mechanical performance, Materials and Structures 37(5) (2004) 365-368.

[28] European Committee for Standarization, BS EN 12697-26: Bituminous mixtures: Test methods for hot mix asphalt, Part 26: Stiffness, British Standards Institution, London, UK, 2012.

[29] European Committee for Standarization, BS EN 12697-25 Bituminous mixtures. Test methods for hot mix asphalt, Part 25: Cyclic compression test, British Standards Institution, London, UK, 2005.

[30] O.L. Oke, A study on the development of guidelines for the production of bitumen emulsion stabilised RAPs for roads in the tropics, University of Nottingham, UK, 2011.

[31] European Committee for Standarization, BS EN 12697-12: Bituminous mixtures. Test methods for hot mix asphalt., Part 12: Determination of the water sensitivity of bituminous specimens., British Standards Institution, London, UK, 2008.

[32] American Association of State Highway Transportation Officials, AASHTO T283: Resistance of compacted bituminous mixture to moisture induced damage standard specifications for transportation materials and methods of sampling and testing, Part II tests, Washington, DC. , 2009.

[33] M. Pettinari, G. Dondi, C. Sangiorgi, O. Hededal, The effect of Cryogenic Crumb Rubber in cold recycled mixes for road pavements, Construction and Building Materials 63 (2014) 249256.

[34] A. Grilli, A. Graziani, M. Bocci, Compactability and thermal sensitivity of cementbitumen-treated materials, Road Materials and Pavement Design 13(4) (2012) 599-617.

[35] A.I. Nassar, M.K. Mohammed, N. Thom, T. Parry, Characterization of High Performance Cold Bitumen Emulsion Mixtures for Surface Courses., International Journal of Pavement Engineering. Manuscript accepted for publication.

[36] B. Lothenbach, T. Matschei, G. Möschner, F.P. Glasser, Thermodynamic modelling of the effect of temperature on the hydration and porosity of Portland cement, Cement and Concrete Research 38(1) (2008) 1-18.

[37] M.K. Mohammed, Multi-scale Response of Sustainable Self-Compacting Concrete (SCC) to Carbonation and Chloride Penetration, University of Nottingham, UK, 2015. 
[38] T.W. Kennedy, J.N. Anagnos, Wet-dry indirect tensile test for evaluating moisture susceptibility of asphalt mixtures, 1984.

[39] A. Aksoy, K. Şamlioglu, S. Tayfur, H. Özen, Effects of various additives on the moisture damage sensitivity of asphalt mixtures, Construction and Building Materials 19(1) (2005) 11-18. [40] S.A. Rizwan, High-performance mortars and concrete using secondary raw materials, Technischen Universitat Bergakademic Freiberg, Germany, 2006.

[41] J. Stark, K. Bollmann, Delayed ettringite formation in concrete, Nordic Concrete Research Meeting, Oslo 1999, pp. 4-28. 